\title{
Comparing Lean Production and Six Sigma Management
}

\author{
Tiehua Chen \\ School of Management, Xi'an University of Science and Technology \\ Shaanxi 710054, China \\ E-mail: chenth@263.net
}

\begin{abstract}
This paper introduces the emergence and the core thought of lean production and six sigma management, comparative and analysis lean production and six sigma management from culture, basic theory, model of operation management, starting point of solving the problems, method of solving the problems, implementation steps, process improvement method, attention object, staff training, cognition of financial effect, etc.

Keywords: Lean production, Six Sigma Management, Total Quality Management

Lean production and Six Sigma management have broad impact, this two methods gave the enterprise that implement successfully huge benefits, both of them exist differences, but also many similarities. In this paper, we will conduct a comparative analysis of the two for the staff to reference and learn from.
\end{abstract}

\section{Lean production and Six Sigma management introduction}

\subsection{Lean Production}

Lean Production originated from the Japanese Toyota Motor Corporation, it developed from the management of the Ford Motor Company that Toyota Motor Corporation is studying. Its core idea is to remove all links of enterprises of non-value-added activities, with less manpower, less equipment, in shorter time and smaller site to create as much as possible the value. to meet customers requirements of the product and service. It emphasis on reducing wastage, so that the reduced value chain of production process are reduced, thereby reducing costs. Lean Production follows the mass production (mass production, MP) mode, this production mode have a greater impact to human society, is a symbol of the new age of industrialization.

\subsection{Six Sigma Management}

Six Sigma management comes from Motorola in the mid-1980s, it summarized out throve practice and on the basis of total quality management and statistics theory, such as the pressure Motorola against Japan enterprise development, in order to improve the quality standard. Its core idea is that it makes all professional work as a process, based on data and facts, use quantitative methods to analysis the factors affecting quality of the flow, identify key factors to improve, and continue to reduce volatility, so that their operation ability comes to be best and achieve customer's satisfaction. It follows the process by streamlining processes, control flow variations, to eliminate the quality variability of products in the process, thereby saving costs. Former General Motors Corporation's president Jack. Welch once pursued six Sigma management which was regarded as a strategy of this company to classify as one of the four great strategies of the company, make the proud achievement, six Sigma management is famous for in the whole world there from. World-class outstanding enterprises competitively adopted hereafter, following Motorola, General Electric (GE), top transnational enterprises of world such as DELL, TOSHIBA, HP, SONY, Citibank (CitiBank), Diness, Hilton Hotel, etc. strengthen management by six Sigma management one after another, improve the management level, lower costs, improve customer's loyalty, increase sales achievements and strengthen the key competitiveness.

\section{Lean production and Six Sigma management contrast}

\subsection{Culture}

The two contain that pursues perfect culture: The lean production regards " perfect " characters as the goal; Six Sigma standards put forward in six Sigma management are a kind of almost perfect quality goal too. But cultural origin difference of the two, thus the two operate level have many in different.

The lean production originated from the cultural environment of Japan, and six Sigma originated from the culture atmosphere of U.S.A.. Occidentals' thought pays attention to logic and analyzes, quality control is managed the influence of the thought by Taylor, emphasize specialization, quality control is finished by the managerial and technical staff of quality, that is to say the professional and technical personnel makes the technical standard, operates the standard, the attendant, according to standard procedure, emphasize specialization, divide the work in 
American-European culture, its responsibility, mutual noninterference of emphasizing every department, managerial relative rigidity. Eastern culture emphasizes the collective, seek cooperation, pay attention to seeking the approval of collective, the society. Japan does not have strong specialization, even technical staff rotates to work in every department such as designing, making, quality control in an enterprise, they emphasize people first, fully arouse the enthusiasm of people, managerial relative flexibility. (Zhou, He \& Gao, 2006, pp. 1-4)

\subsection{Theoretical foundations}

Six Sigma which is based on TQM and statistics play an importance to the facts and data, by quantifiable indicators and analysis to the index to avoid the use their experience, intuitive, or take it for granted which are used to solve the problems. In practice, it combines many traditional statistical methods and tools such as QFD (Quality Function Deployment), FMEA (Failure Mode and Effects Analysis), SPC (statistical process control), MSA (Measurement System Analysis), ANOVE (analysis of variance), DOE (design of experiments), regression analysis, hypothesis testing, and so on.

Lean which is on the basis of Industrial Engineering solves the problem more dependently on the experience and intuition of experts to solve the problem, it is commonly used tools: single-piece flow, pulling System (billboards), Just In Time (JIT), Value Chain Management, TPM (Total Production Maintenance), SMED (Quick Die Change), the balanced production lines, prevent errors, workplace Organization (Workplace organization), 5S, customer value flow analysis, motion analysis and time to determine technical layout of the factory facilities, Jidoka (automation ) and the prevention of errors, more training to T, SS / TPM, and so many other technologies.

\subsection{Operational management pattern}

Their implementation is similar to PDCA cycle which is brought up by DAI Ming, is process-based management. Lean production is based on the model which improve their management on the scene, which distributes resources effectively by emphasizing the importance of the scene, uses systems perspective, is based on the value added processes to consider the entire production chain management, and is based on the whole production system. Six Sigma is a project-based management model, it DMAIC process-the implementation of the systematic completion of the project objectives, it uses in top-down management style, advocates, Black Belts, Green belt, staff, organic combination of grade level (Zhou, He \& Gao, 2006, pp. 1-4).

\subsection{Starting point of solving problems}

Lean production puts reducing wastes (mainly seven kinds: to correct mistakes, excessive production, material transfer, handling, inventory, waiting, mobile) as the starting point, through the value stream analysis, it find the breakthrough point, and suit the remedy to the cases.

Six Sigma management puts the need to satisfy customers as the starting point, starts from the policy objectives through top-down, and selects the most influential issues from all issues which needs to be resolved as Six Sigma implementation issues.

\subsection{Analysis of the methods}

Lean production puts visual management into effect, adopts direct approach which can quickly resolve the problems. Six Sigma focuses on quantitative analysis, which can be found deep-seated complex issues. Through quantification and analysis of indicators to avoid using their experience to solve the problem.

\subsection{Implementation of the steps}

Implementation of Lean production has no fixed steps. A lot of enterprises start from 5S, because $5 \mathrm{~S}$ implementation success can pave the good way for other Management implementation of Lean Production. Some enterprises directly analyze from the Value Stream Mapping (Value Stream Mapping), some enterprises implement some small-scale QCC activities. It consists of enterprises under their own management level used to determine what steps to implement lean production, as long as the focus on "value stream" to facilitate implementation on it. After the system Lean product training, we can then implement various places in the enterprise from high-level managers to the basic workers, can be at the same time.

The implementation of Six Sigma have relatively fixed steps, the basic steps of the implementation of Six Sigma management are as follows: (1) Identify core processes and key customers; (2) Define customer demand, (3) assess the current performance; (4) identify priorities, analyze and implement improvement. Six Sigma stressed accordance with the steps.

\subsection{Process Improvement modalities}

Both are continuous improvement, stressed that process improvement is not the only time to complete, organizations must constantly diagnose and improve on the business process. But both improved in different ways.

Lean Production adopts gradual improvement (Kaizen) strategy, which does not require large investments by 
emphasizing the established technology along the path, through continuous improvement to provide better quality of products or services. Six Sigma management strategy make each item having a breakthrough success by using breakthrough improvements, organizations can bring great financial benefits, their input also is larger (He, Zhou \& Gao, 2006, pp. 13-17).

\subsection{Concern area}

Lean Production concern is the elimination of waste, which eliminate waste through its focus on shortening the production cycle, reducing inventory, improving the efficiency of processes, realizing the level of products and lowering consumption of resources. Six Sigma concern is variability, which seeks to reduce and eliminate volatility. The elimination of all waste and reduction are based on the variation in value. Variability is a way to generate waste, reducing variability can reduce waste.

Lean product and Six Sigma management have two different groups of concern, but both are based on the value. Variability is a way to generate waste, reducing variability can reduce waste.

\subsection{Training}

Both "Lean" and "Six Sigma" stress the importance of improving the process, it has paid great attention to staff training and management, but the two different emphases.

Lean Production attaches great importance to the on-site training for the average staff, training is mainly through "learning", each concentrated training has a relatively short time, usually one to two hours, immediate site improvements after the training can enhance the employees at the scene skills, which make employees gain more and rotational training ability through a variety of skills.

The Six Sigma management focus on systematic manageable personnel training, to resolve it through their own professional training of experts, such as Six Sigma Black Belt training for a period of about 20 days, after four to five months, to complete training for tools and methods related to all phases of DMAIC. Six Sigma emphasizes the role of black belt and green belt, asking them to have more statistical knowledge and skills dealing with problems.

\subsection{Financial results awareness}

Through the reduction or elimination of waste, lean production, subjectively, has a contribution in the financial management of enterprises. But without a corresponding analysis and planning requirement, lean production is not concerned about how much it can contribution in the end.

Six Sigma management is a marked characteristic of the financial outcome-oriented. It uses Pareto law or other tools to select right implementation of the subject to maximize benefit, while subjects, which don't product or have fewer benefit are not preference.

\section{Conclusion}

Through comparison and analysis above, we can conclude that, Lean production and Six Sigma management, in the culture pursuit, ultimate objective, continuous improvement, understanding of human, strategic requirements, etc, are consistent (Zhou, He \& Gao, 2006, pp. 1-4). The two have a main distinction in the operating layer, such as the model of operation and management, the starting points and methods to solve the problem, implementation steps, focusing of specific implement and training, cognitive of financial effect, process improvement strategies, and concerns and so on. But through contrast, we can see that, these differences are not antagonistic but complementary. If integrating and applying the two, organization business process will achieve better conditions; organization ability of adapting to market and competitive will be improved gradually, which better meet the needs of customers.

\section{References}

Zhou, Hu, He, Zhen \& Gao, Xuefeng. (2006). The contrast and integration of Lean production and Six Sigma management. Industrial engineering, 6, 1-4.

He, Zhen, Zhou, Hu \& Gao, Xuefeng. (2006). Lean Six Sigma and its implementation. Journal of Xi'an University of Electronic Science and Technology (Social Sciences), 1,13-17. 